\title{
PENINGKATAN SUHU BAYI BARU LAHIR DAN IBU MELALUI INISIASI MENYUSU DINI
}

\author{
Yuyun Setyorini ${ }^{1,2^{*}}$, Yeni Rustina ${ }^{3}$, Yusron Nasution ${ }^{4}$ \\ 1. Jurusan Keperawatan Poltekkes Kemenkes Surakarta, Solo 57131, Indonesia \\ 2. Program Studi Magister Fakultas Ilmu Keperawatan Universitas Indonesia, Depok 16424, Indonesia \\ 3. Fakultas Ilmu Keperawatan Universitas Indonesia, Depok 16424, Indonesia \\ 4. Fakultas Kesehatan Masyarakat Universitas Indonesia, Depok 16424, Indonesia \\ *Email: setyorini.yuyun@ymail.com
}

\begin{abstract}
Abstrak
Salah satu manfaat inisiasi menyusu dini (IMD) adalah mempertahankan suhu tubuh bayi. Tujuan penelitian ini adalah mengidentifikasi pengaruh IMD terhadap suhu tubuh bayi dan suhu tubuh ibu. Penelitian yang menggunakan desain kuasi eksperimen nonequivalent with control group melibatkan 35 responden untuk setiap kelompok. Tindakan yang dilakukan adalah IMD sampai bayi menemukan puting dan menyusu sendiri. Hasil menunjukkan adanya perbedaan bermakna antara suhu tubuh bayi sebelum dan sesudah tindakan $(\mathrm{p}=0,000, \alpha=0,05)$, dan antara suhu tubuh ibu sebelum dan sesudah tindakan $(\mathrm{p}=$ $0,000, \alpha=0,05)$. Terdapat perbedaan bermakna pada suhu tubuh bayi pada kedua kelompok $(p=0,000, \alpha=0,05)$, dan suhu tubuh ibu pada kedua kelompok $(p=0,005, \alpha=0,05)$. Penelitian ini memperkuat fakta bahwa IMD mempengaruhi suhu tubuh ibu sehingga stabilitas suhu tubuh bayi dapat dipertahankan.
\end{abstract}

Kata kunci: inisiasi menyusu dini, stabilitas suhu tubuh bayi, suhu tubuh ibu

Abstract

One of the effects of early initiation of breastfeeding (EIB) is to maintain the newborn 's temperature. The purpose of this study is to identify the influence of EIB on the temperature of the newborn and the mother. The study, using a quasi experimental design with nonequivalent control group involved 35 respondents for each group. The intervention taken was EIB until the baby finds mother's nipple and suckle it. The results showed that significant differences between the newborn's temperature before and after intervention $(p=0,000, \alpha=0,05)$, and between the mother's temperature before and after intervention ( $p=$ $0,000, \alpha=0,05)$. There are significant differences in the newborn's temperature in both groups $(p=0,000, \alpha=0,05)$, and the mother's temperature in both groups $(p=0,005, \alpha=0,05)$. This study strengthens the fact that EIB affects the mother's temperature to maintain the stability of the newborn's temperature.

Keywords: early initiation of breastfeeding, newborn temperature, maternal temperature

\section{Pendahuluan}

Menyusui sangat bermanfaat bagi ibu maupun bayi. Salah satu upaya untuk mempertahankan keberlanjutan menyusui tersebut adalah dengan inisiasi menyusu dini (IMD). IMD dilakukan segera setelah bayi lahir, dipotong tali pusatnya dan dikeringkan kemudian bayi diletakkan di dada ibu sampai bayi tersebut dapat menemukan puting susu dan menyusu dengan sendirinya tanpa adanya bantuan dari orang lain (Roesli, 2008).

Kaitan antara IMD dengan berkurangnya masalah menyusui selama di rumah sakit belum dilakukan studi. Namun, studi terdahulu melaporkan bahwa IMD meningkatkan keberhasilan menyusui hingga dua sampai tiga bulan (Rowe-Murray \& Fisher, 2002).

Edmond, Zandoh, Quigley, Etego, Agyei, dan Kirkwood (2006) melaporkan bahwa 22\% kematian bayi usia di bawah 28 hari dapat dicegah dengan pemberian ASI eksklusif sejak umur satu hari. Organisasi Kesehatan Dunia (WHO) mencanangkan pentingnya IMD pada pekan ASI sedunia Agustus 2007, yang bertema "menyusui satu jam pertama kehidupan, menyelamatkan lebih dari satu juta bayi”. Sejak saat itu IMD disepakati untuk dilaksanakan di berbagai negara termasuk Indonesia (Depkes, 2007). 
IMD dapat memberikan manfaat lainnya baik bagi bayi maupun bagi ibu, selain manfaat yang berkaitan dengan menyusui. Bagi bayi, IMD memberikan kehangatan melalui kontak dengan kulit ibu, memberi kenyamanan, membantu adaptasi metabolisme, dan mengurangi kejadian diare dan infeksi saluran napas bagian bawah. IMD bagi ibu membantu pelepasan plasenta dan kontraksi uterus, meningkatkan ikatan kasih sayang ibu - bayi, serta mengurangi stres dan kecemasan (IBFAN-Asia, 2007; Chair, 2007; Klaus, 1999; Lauer, Betran, Barros, \& deOnis, 2006; Gangal, 2007; Tessier, Cristo, Velez \& Giron, 1998).

Suhu ibu merupakan merupakan sumber panas yang murah. Bayi ketika baru lahir kondisi pengaturan suhunya belum matang terutama pada bayi prematur dan berat lahirnya rendah sehingga memerlukan bantuan untuk menghangatkan hingga kondisinya stabil. Kulit ibu yang hangat dapat menjadi media untuk menghangatkan bayi. Pada IMD bayi diletakkan pada kulit ibu sehingga memberikan kehangatan pada bayi. Untuk itu perlu dilakukan studi untuk mengidentifikasi pengaruh IMD terhadap suhu tubuh bayi maupun suhu tubuh ibu.

Tujuan penelitian ini adalah untuk mengetahui pengaruh inisiasi menyusu dini terhadap suhu tubuh pada bayi baru lahir dan suhu tubuh ibu. Hipotesis yang diuji adalah ada pengaruh IMD pada suhu tubuh bayi, ada pengaruh IMD pada suhu tubuh ibu, ada perbedaan suhu tubuh antara kelompok intervensi dan kontrol dan ada perbedaan suhu tubuh ibu pada kelompok intervensi dan kontrol.

\section{Metode}

Penelitian ini menggunakan kuasi eksperimen dengan rancangan nonequivalent with control group. Pada kelompok intervensi dilakukan IMD sedangkan pada kelompok kontrol tidak. Populasinya adalah bayi yang baru lahir dan ibunya. Besar sampel yang diambil dengan convenience sampling yaitu 35 responden untuk tiap kelompok. Adapun kriteria inklusinya, ibu dengan kehamilan aterm, kondisi ibu (tidak mengalami perdarahan atau komplikasi lainnya), direncanakan persalinan normal, bayi lahir dengan persalinan normal (spontan), dan nilai APGAR pada menit pertama $7-10$.

Penelitian dilaksanakan di dua tempat persalinan di Kota Solo, satu untuk kelompok intervensi dan lainnya untuk kelompok kontrol. Setelah mendapatkan persetujuan dari komite etik, dibutuhkan waktu sekitar tiga bulan untuk proses lapangan.

Alat pengumpulan data yang digunakan adalah lembar isian tentang data demografi dan observasi untuk pencatatan suhu dan termometer infrared. Analisis data dilakukan dengan bantuan perangkat lunak computer dengan uji independen dengan alpha 0,05 dan uji regresi linier ganda.

\section{Hasil}

Karakteristik responden terdiri dari berat badan bayi baru lahir (BBL), umur, dan pendidikan ibu. Secara lengkap dapat dilihat pada tabel 1 .

Tabel 1. Karakteristik Responden

\begin{tabular}{lcccc}
\hline \multicolumn{1}{c}{ Karakteristik } & \multicolumn{2}{c}{ Kelompok Intervensi } & \multicolumn{2}{c}{ Kelompok Kontrol } \\
\% & F & \% & F & \% \\
\hline BBL & 19 & 54,3 & 19 & 57,3 \\
- $2700-3000 \mathrm{~g}$ & 16 & 45,7 & 16 & 45,7 \\
- $>3000-3600 \mathrm{~g}$ & & & & \\
Umur Ibu & 26 & 74.3 & 25 & 71,4 \\
- 20-29 tahun & 9 & 25,7 & 10 & 28,6 \\
- 29-35 tahun & & & & \\
Pendidikan Ibu & 20 & 57,1 & 21 & 60 \\
- Rendah & 15 & 42,9 & 14 & 40 \\
\hline Tinggi & & & \\
\hline
\end{tabular}


Pada uji homogenitas kedua kelompok ditemukan $p=0,97$ pada nilai rerata umur ibu dan $p=0,81$ pada pendidikan ibu, artinya kedua kelompok tersebut homogen. Sedangkan, rerata suhu bayi sebelum IMD pada kelompok intervensi $p=0,165$ dan 0,973 yang artinya tidak ada perbedaan bermakna antara kelompok intervensi dan kelompok kontrol.

\section{Perbandingan Suhu Tubuh Sebelum dan Sesudah Intervensi}

Pada kelompok intervensi rerata suhu tubuh bayi sebelum dilakukan tindakan IMD (pre-test) ialah $36,09^{\circ} \mathrm{C}$ dengan standar deviasi (SD) $0,76^{\circ} \mathrm{C}$. Setelah dilakukan tindakan IMD (post-test) didapatkan rerata suhu tubuh bayi $36,63^{\circ} \mathrm{C}$ dengan SD 0,42 . Terlihat perbedaan rerata antara pre-test dan posttest adalah 0,54 dengan SD 0,524.

Hasil analisis dapat menyimpulkan adanya perbedaan yang bermakna suhu tubuh bayi antara sebelum dan sesudah IMD ( $p=0,000, \alpha=0,05)$. Hal ini menunjukkan adanya pengaruh IMD pada suhu tubuh bayi. Rerata suhu tubuh ibu sebelum dilakukan IMD (pre-test) adalah $36,30^{\circ} \mathrm{C}$ dengan SD 0,32. Pada pengukuran suhu tubuh ibu setelah IMD (post-test) reratanya $36,80^{\circ} \mathrm{C}$ dengan $\mathrm{SD}=$ 0,23 .

Terlihat rerata perbedaan antara pre-test dan posttest adalah 0,49 dengan $\mathrm{SD}=0,39$. Hasil uji statistik dapat disimpulkan bahwa ada perbedaan yang bermakna antara suhu tubuh ibu pada sebelum dan sesudah IMD ( $p=0,000, \alpha=0,05)$ (lihat pada tabel 2).
Pada kelompok kontrol rerata suhu tubuh bayi lahir pre-test adalah $36,32^{\circ} \mathrm{C}$ dengan SD 0,58. Pada post-test didapatkan rerata $36,06^{\circ} \mathrm{C}$ dengan SD 0,39. Terlihat rerata perbedaan antara pre-test dan post-test $-0,26^{\circ} \mathrm{C}$ dengan $\mathrm{SD}=0,39$. Hal ini menunjukkan bahwa terjadi penurunan suhu $0,26^{\circ} \mathrm{C}$. Rerata suhu tubuh ibu pada pre-test adalah $36,30^{\circ} \mathrm{C}$ dengan $\mathrm{SD}=0,37$.

Pada post-test didapatkan rerata $36,80^{\circ} \mathrm{C}$ dengan SD 0,31. Terlihat rerata perbedaan antara pre-test dan post-test adalah $0,3^{\circ} \mathrm{C}$ dengan SD 0,32. Hasil uji statistik dapat disimpulkan bahwa ada perbedaan yang bermakna antara suhu tubuh ibu pada pengukuran pre-test dan post-test $(\mathrm{p}=0,000, \alpha=$ $0,05)$ (lihat pada tabel 3).

\section{Perbedaan suhu tubuh pada post-test}

Rerata suhu tubuh bayi sesudah IMD (post-test) adalah $36,63^{\circ} \mathrm{C}$ dengan SD 0,42 , sedangkan untuk bayi yang tidak IMD rerata suhu tubuhnya adalah $36,06^{\circ} \mathrm{C}$ dengan SD 0,39. Hasil uji statistik dengan uji $\mathrm{t}$ independen didapatkan ada perbedaan yang bermakna pada rerata suhu tubuh bayi antara kelompok intervensi dengan kelompok $\operatorname{kontrol}(\mathrm{p}=$ $0,000, \alpha=0,05)$.

Rerata suhu tubuh ibu kelompok intervensi pada post-test adalah $36,80^{\circ} \mathrm{C}$ dengan $\mathrm{SD}=0,23$, sedangkan untuk kelompok kontrol rerata suhu tubuh ibu adalah $36,60^{\circ} \mathrm{C}$ dengan $\mathrm{SD}=0,31$. Hasil uji $\mathrm{t}$ independen didapatkan ada perbedaan yang bermakna antara suhu tubuh ibu pada kedua kelompok ( $p=0,005, \alpha=0,05)$ (dapat dilihat pada tabel 4).

Tabel 2. Distribusi Suhu Tubuh Pre-test dan Post-test pada Kelompok Intervensi

\begin{tabular}{lccccc}
\hline \multicolumn{1}{c}{ Variabel } & n & Rerata & Rerata perbedaan & SD & $p$ \\
\hline Suhu Bayi & 35 & 36,09 & 0,54 & 0,76 & 0,000 \\
$\begin{array}{l}\text { Pre-test } \\
\text { Posttest }\end{array}$ & & 36,63 & & 0,42 & \\
Suhu Ibu & & & & 0,32 & 0,000 \\
Pre-test & 35 & 36,30 & 0,49 & 0,23 & \\
Post-test & & 36,80 & & & \\
\hline
\end{tabular}




\section{Pembahasan}

Penelitian ini menunjukkan bahwa terdapat pengaruh inisiasi menyusu dini (IMD) terhadap suhu tubuh bayi. Terjadinya peningkatan suhu pada kelompok intervensi disebabkan oleh karena kulit bayi menempel pada kulit ibu sehingga terjadi konduksi, yaitu perpindahan panas secara langsung dari ibu ke bayi.

Selain karena adanya konduksi, juga karena pada saat bayi diletakkan di dada ibu, ia bergerak merangkak sambil mencari puting susu ibu. Adanya gerakan ini dapat merangsang produksi panas sehingga susunan saraf pusat akan menstimulasi saraf simpatis untuk menggunakan cadangan lemak coklat yang merupakan sumber panas pada bayi (Chair, 2007; Christensson, Bhat, Amadi, Eriksson, \& Hojer, 1998; Ludington-Hoe \& Golant, 1993).

Hasil uji homogenitas didapatkan bahwa kedua varian sama atau homogen, berarti menunjukkan bahwa peningkatan suhu tubuh ibu pada kelompok intervensi itu karena IMD. IMD bermanfaat memberi kehangatan pada ibu yang selanjutnya dapat memberikan pengaruh pada suhu tubuh bayi (Chair, 2007; Ludington-Hoe \& Golant, 1993).

Akan tetapi, pada penelitan ini tidak terlihat adanya sinkronisasi atau penyesuaian antara suhu tubuh ibu dengan suhu tubuh bayi. Hasil ini tidak sesuai dengan Ludington-Hoe dan Golant, (1993) yang menyatakan bahwa adanya fenomena sinkronisasi termal ibu dan bayi. Pada masa nifas, ibu mengalami peningkatan suhu tubuh kurang lebih $0,5^{\circ} \mathrm{C}$ dari keadaan normal. Setelah 12 jam pertama suhu tubuh ibu akan kembali normal.

Pada saat ibu bersalin, salah satu faktor yang berperan adalah tenaga. Tenaga yang digunakan pada saat ibu bersalin meningkat sehingga terjadi peningkatan laju metabolisme. Peningkatan laju metabolisme ini membuat susunan saraf pusat menstimuli saraf simpatis untuk menggunakan cadangan makanan atau lemak diubah menjadi energi. Hal ini yang menyebabkan suhu tubuh ibu nifas meningkat. Peningkatan suhu tubuh ibu ini normalnya terjadi pada hari pertama nifas (Bobak, Lowdermilk, \& Jensen, 1999/2005).

Penelitian ini memberikan hasil yang menarik karena suhu tubuh bayi pada post-test mengalami peningkatan yang bermakna. Hasil ini sejalan dengan penelitian atau literatur sebelumnya yang menyebutkan bahwa salah satu manfaat IMD adalah memberikan kehangatan bagi bayi (Chair, 2007; Gangal, 2007; IBFAN-Asia, 2007; Klaus, 1999; Lauer, Betran, Barros, \& de Onis, 2006; Tessier, Cristo, Velez \& Giron, 1998).

Sementara pada kelompok kontrol sebaliknya terjadi penurunan suhu bayi. Terjadinya penurunan suhu tersebut dimungkinkan karena beberapa faktor, antara lain karena proses evaporasi cairan ketuban yang menempel pada tubuh bayi. Selain itu, proses radiasi yang membuat panas tubuh pada bayi baru lahir memancar ke lingkungan sekitar dalam waktu yang cepat, atau proses konveksi yang membuat panas pada tubuh bayi hilang karena aliran udara di sekeliling ruang bersalin yang dingin.

Tabel 3. Distribusi Suhu Tubuh Pre-test dan Post-test pada Kelompok Kontrol

\begin{tabular}{lcccc}
\hline \multicolumn{1}{c}{ Variabel } & $\mathbf{n}$ & Rerata & SD & p \\
\hline Suhu Bayi & & & & \\
Pre-test & 35 & 36,32 & 0,58 & 0,000 \\
Post-test & & 36,06 & 0,39 & \\
Suhu Ibu & & & & 0,000 \\
Pre-test & 35 & 36,30 & 0,37 & \\
Post-test & & 36,60 & 0,31 & \\
\hline
\end{tabular}


Sedangkan, faktor yang ada pada bayi, karena pusat pengatur suhu bayi yang belum berfungsi dengan baik, permukaan tubuh bayi lebih luas, tubuh bayi terlalu kecil untuk memproduksi dan menyimpan panas. Hal ini sesuai dengan pendapat Olds dan London (1999), bahwa pada saat kelahiran suhu tubuh bayi akan menurun $2-3^{\circ} \mathrm{C}$ terutama karena evaporasi cairan ketuban.

Penelitian ini menunjukkan bahwa suhu ibu pada kelompok kontrol mengalami peningkatan sama seperti pada kelompok intervensi, tetapi peningkatan pada kelompok intervensi lebih tinggi dibandingkan dengan kelompok kontrol. Pada kelompok intervensi meningkat $0,49^{\circ} \mathrm{C}$ sedangkan pada kelompok kontrol meningkat $0,3^{\circ} \mathrm{C}$.

Dengan demikian perubahan suhu tubuh pada ibu selain karena faktor nifas juga karena adanya tindakan IMD yang dilakukan. Hal ini sesuai dengan pendapat Bobak, Lowdermilk, dan Jensen (1999/2005), mengenai peningkatan suhu tubuh ibu nifas yang normalnya terjadi pada hari pertama nifas.

Hasil penelitian ini melaporkan bahwa IMD berpengaruh terhadap suhu tubuh bayi. Hal ini membuktikan bahwa IMD dapat memberikan kehangatan kepada bayi sehingga bayi terhindar dari resiko hipotermia atau terjadi penurunan suhu tubuh.

Wilhelm (2005), mengemukakan tentang efek dari metode kanguru terhadap suhu tubuh yang menunjukkan bahwa metode kanguru sangat efektif untuk mencegah terjadinya hipotermia pada bayi prematur. Prinsip dari metode ini adalah skin to skin contact yang mirip dengan salah satu prinsip IMD.
Suhu tubuh ibu ternyata merupakan sumber panas, dengan melakukan skin to skin contact maka panas ini dapat ditransfer ke bayi. Suhu tubuh ibu dengan IMD mengalami peningkatan yang lebih tinggi bila dibandingkan dengan suhu tubuh ibu yang tidak IMD.

Hasil penelitian ini sesuai dengan pendapat Ludington-Hoe dan Golant (1993), bahwa terdapat fenomena yang menarik tentang pengaturan suhu ibu. Suhu tubuh ibu akan meningkat bila bayi mulai dingin dan bila bayi telah hangat, maka suhu tubuh ibu akan menurun kembali. Hal ini menunjukkan bahwa ibu dapat menjadi mediator yang baik bagi bayinya dan bayi baru lahir tidak selalu harus mendapat perawatan dengan inkubator (Suradi \& Yanuarso, 2007).

Ibu dapat berfungsi sebagai mediator panas dan terjadi proses bonding attatchment sehingga bayi merasa lebih nyaman berada di pelukan ibunya. Selain itu, bayi juga dapat bergerak merangkak untuk menemukan puting susu ibu dan menyusu dengan sendirinya sehingga proses laktasi pun dapat berjalan dengan lancar (Rowe-Murray \& Fisher, 2002). Berbagai faktor lain yang mungkin mempengaruhi terjadinya perubahan suhu tubuh bayi seperti berat badan ibu dan suhu lingkungan tidak diperhatikan pada penelitian ini.

\section{Kesimpulan}

Penelitian ini menjawab semua hipotesis. Melalui penelitian ini tampak ada pengaruh IMD terhadap peningkatan suhu tubuh bayi. Kemudian IMD juga memberikan pengaruh peningkatan suhu tubuh ibu.

Tabel 4. Distribusi Suhu Tubuh Post-test pada Kelompok Intervensi dan Kelompok Kontrol

\begin{tabular}{lcccc}
\hline \multicolumn{1}{c}{ Variabel } & n & Rerata & SD & p \\
\hline Suhu Bayi & & & & \\
Kelompok Intervensi & 35 & 36,63 & 0,42 & 0,000 \\
Kelompok Kontrol & 35 & 36,06 & 0,39 & \\
Suhu Ibu & & & & 0,005 \\
Kelompok Intervensi & 35 & 36,80 & 0,23 & \\
Kelompok Kontrol & 35 & 36,60 & 0,31 & \\
\hline
\end{tabular}


Jika dibandingkan antara kelompok intervensi dan kontrol ada perbedaan bermakna pada suhu tubuh bayi. Begitu pula pada suhu tubuh ibu ditemukan ada perbedaan pada kelompok intervensi dan kontrol.

Hasil penelitian ini memperkuat justifikasi keharusan penerapan IMD di setiap institusi kesehatan yang menyediakan pelayanan pertolongan persalinan. IMD tidak saja memberikan manfaat pada keberlanjutan pemberian ASI tetapi juga memberikan manfaat stabilisasi suhu pada bayi baru lahir.

Penelitian ini sebaiknya dilanjutkan dengan penelitian lainnya yang dapat menguji berbagai faktor yang mungkin mempengaruhi suhu tubuh bayi baik dari bayi sendiri, ibu maupun dari lingkungannya. IMD juga seharusnya menempati porsi yang cukup dalam kurikulum pendidikan setiap tenaga kesehatan yang berhubungan dengan kesehatan ibu dan anak (AT, INR, HR).

\section{Referensi}

Bobak, I.M., Lowdermilk, D.L., \& Jensen, M.D. (2005). Keperawatan maternitas. (M.A. Wijayarini, Trans). Jakarta, Indonesia: EGC. (Buku asli diterbitkan 1999).

Chair, I. (2007). Metode kanguru untuk bayi prematur. Diperoleh dari http://www.halal guide.info.

Christensson, K., Bhat, B., Amadi, B., Eriksson, B., \& Hojer, B. (1998). Randomised study of skinto-skin versus incubator care for rewarming low risk hypothermic neonates. The Lancet, 352 (5), 11-15. (PMID: 9798589).

Depkes RI. (2007). Pekan ASI sedunia 2007: Hak bayi untuk menyusui agar dipenuhi. Diperoleh dari http://www.indonesia.go.id/id/index.php? option $=$ com_content\&task $=$ view\&id $=5413$.

Edmond, K.M., Zandoh, C., Quigley, M.A., Etego, S.A., Agyei, S.O., \& Kirkwood, B.R. (2006). Delayed breastfeeding initiation increases risk of neonatal mortality. American Academy of Pediatrics, 117 (13), 380-386. DOI: 10.1542/ peds.2005-1496
Gangal, P. (2007). Breast crawl: Initiation of breastfeeding by breast crawl. New Delhi: UNICEF Maharashtra.

IBFAN-Asia. (2007). Timely initiation of breastfeeding within 1st hour of birth: Giving the best chance of life and health! Diperoleh dari http:// www.ibfanasia.org/Article/timely-ib.pdf.

Klaus, M. (1998). Mother and infant: Early emotional ties. American Academy of Pediatrics, 102 (15), 1244-1246. Doi: 10.1542/peds.102.5. SE1.1244

Lauer, J.A., Betran, A.P., Barros, A.J., \& deOnis, M. (2006). Death and years of life lost due to suboptimal breastfeeding among children in developing world: A global ecological risk assessment. Public Health Nutrition, (9), 673685. Doi: 10.1079/PHN2005891.

Olds, S.B., \& London, M.L. (1999). Maternalnewborn nursing: A family and communitybased approach (6th Ed.). New Jersey: Prentice Hall.

Rowe-Murray, H. J., \& Fisher, J. (2002). Baby friendly hospital practices: Cesarean section is a persistent barrier to early initiation of breastfeeding. Birth, 29, 124-130. (PMID: 12000413)

Roesli, U. (2008). Inisiasi menyusu dini: Plus ASI eksklusif. Jakarta, Indonesia: Pustaka Bunda.

Suradi, R., \& Yanuarso, P. (2007). Metode kanguru sebagai pengganti inkubator bagi bayi berat lahir rendah. Diperoleh dari http:// www.idai.or.id.

Tessier, R., Cristo, M., Velez, S., \& Giron, M. (1998). Kangaroo mother care and the bonding hypothesis. Pediatrics, 102 (3), 1-8. (PMID: 9685462)

Wilhelm, P. (2005). The effect of early kangaroo care on breast skin temperature, distress, and breastmilk production in mothers of premature infants (Doctoral dissertation, University of Nebraska Medical Center). Diperoleh dari ProQuest Digital Dissertations database. 